\title{
La comunicación digital de la Unión Europea en relación con la ciudadanía
}

\section{Digital Communications at European Union Related to Citizenship}

\author{
María Asunción Gálvez Caja ${ }^{1}$ \\ Universidad Internacional de La Rioja (España)
}

Recibido: 16-07-20

Aceptado: 09-09-20

\section{Resumen}

En un intento de reflexionar sobre la conexión que hay entre esferas aparentemente tan distintas como el universo ciudadano y el universo institucional, este artículo trata de describir cómo es la comunicación institucional de la Unión Europa en relación con los individuos en su papel de ciudadanos y usuarios, por tanto, desde el punto de vista exclusivamente digital.

Este análisis se realiza sobre una selección representativa del conjunto de las unidades que componen la Unión Europea mediante el estudio de sus páginas web con el fin de averiguar si cada uno de estos cuerpos está "ciudadanizado" y si existe un espacio de diálogo e interacción destinado a solucionar todo tipo de gestiones y trámites, así como a satisfacer las necesidades de información que como europeos podemos tener.

Palabras-clave: Ciudadanización, instituciones europeas, Unión Europea, Parlamento Europeo, Presidencia del Consejo Europeo.

\footnotetext{
${ }^{1}$ (asuncion.galvez@unir.net). Doctora en Ciencias de la Información por la Universidad Complutense de Madrid, Departamento de Comunicación Audiovisual y Publicidad I (2006-2013). Actualmente profesora asociada en la Facultad de Ciencias de la Información (UCM); en UNIR (Universidad Internacional de La Rioja) profesora y directora académica del Master Universitario en Comunicación y Marketing Político. Entre sus publicaciones cabe destacar "Creatividad digital en comunicación política: estudio de la segunda campaña presidencial de Barack Obama en Facebook y WhiteHouse.gov.", en AdResearch (ESIC), n ${ }^{\circ}$ 14, Vol. 14, 2016; "Barack Obama como tech-president: factores que lo definen", en Palabras, 2017; Capítulo en libro titulado "Experiencias, aprendizajes y lecciones sobre la comunicación política on line". Consultoría Política, Universidad Camilo José Cela y CIGMAP Centro Internacional de Gobierno y Marketing Político. Madrid, 2016 (Galardonado con el "Napolitan Victory Awards 2017" a mejor libro del año).

ORCID: https://orcid.org/0000-0002-2444-9377.
} 


\begin{abstract}
Trying to reflex about what connexion is between so-called different spheres as citizenship and institutional, this paper pretends to describe the institutional and digital communications made by the European Union, related to individuals as citizens and users too. We will make it from a digital point of view as well.

To achieve this goal, we will select a group of the more representative institutions of the European Union, through the analysis and study of every website. We are aimed to discover how much citizenship permeates institutions. We want to discover if there is a common space to dialog and interact between both parts, allowing citizens to manage all their transactions and processes, and find the information they look up too as Europeans.
\end{abstract}

Key-words: Citizenship, European Institutions, European Union, European Parliament, Presidency of the European Council.

\title{
1. Introducción
}

Este artículo está destinado a describir la comunicación digital de los cuerpos que componen la Unión Europea, para lo cual hemos seleccionado los siguientes: Parlamento Europeo, Consejo Europeo de la Unión, Presidencia del Consejo de la Unión Europa, Comisión Europea, Corte de Justicia de la Unión Europea, y Banco Central Europeo. Todas las demás instituciones se analizan de manera general: Corte Europea de Auditores, Servicio de Acción Externa de la Unión Europea, Comité Social de la Unión Europea, Comité de Regiones de la Unión Europea, Banco Europeo de Inversiones, Supervisor Europeo de Protección de Datos y Board Europeo de Protección de Datos.

Si bien esta problemática se ha abordado de manera general y no es nueva, no parece que haya signos evidentes de una disección tan prolija como la que se presenta sobre el desarrollo digital de las instituciones europeas como preocupación manifiesta. Gozálvez (2011) hace una aproximación que a nosotros nos concierne desde el punto de vista de los ciudadanos, porque insiste en la necesidad de que cada uno esté educado en el uso responsable y cívico de las tecnologías comunicativas, para favorecer procesos de participación y deliberación que funcionan como sustento de una democracia viva. En este sentido alerta sobre el peligro de reducir la dimensión del ciudadano a consumidores digitales, porque renuncian a oportunidades para enfrentarse a opiniones relacionadas con la vida pública, ya sea de tipo político, cultural, etc.

Friedmann y Llorens (2000), también desde la perspectiva del ciudadano, estudian la participación como factor que requiere "una doble credibilidad: 
la que se considera honesta y transparente en su funcionamiento y gasto, flexible y dialogante en su estilo de relación con la ciudadanía", entendiendo estos factores como condiciones. Torres-Gastelú et al (2019) integran el factor digital de manera transversal en el concepto de ciudadanía, explicando que los gobiernos de muchos países han dedicado sus esfuerzos para asegurar la accesibilidad y uso eficiente de la tecnología y sus recursos digitales por parte de la población.

Sebastián (1997) ilustra este tema ya desde el lado de las instituciones europeas, remontándose a 1993, que fue cuando el Consejo Europeo decidió "articular esta sociedad a partir de los sistemas de comunicación, la información y las nuevas tecnologías de la información, que juntas están incubando una revolución que dota al ser humano de nuevas fronteras económicas, culturales, sociales y laborales". Desde el ángulo de la ciberdemocracia, Sierra (2012) apunta que "los estudios sobre ciberdemocracia demuestran, en efecto, que los nuevos medios de comunicación ofrecen posibilidades no exploradas de gobernabilidad, potenciación y desarrollo cultural y socioeconómico descentralizados". Entiende que

con el cambio de soporte material de la cultura (de los medios analógicos a los sistemas digitales) y su apropiación por el tejido social, la ciudadanía cuenta ciertamente con un amplio abanico de recursos de expresión y representación informativa dispuestos para explorar y vivir la democracia de forma creativa y abierta a la experimentación para el empoderamiento y autoorganización social (Sierra, 2012).

Son ciertamente afines las aproximaciones que hace Sierra (2012) a nuestro objeto de estudio porque entiende la Unión Europea como creadora del eGobierno con el fin de que las autoridades locales tengan una mejor gobernabilidad, optimizando así la eficiencia administrativa, la transparencia pública, la apertura institucional y la participación democrática. Aun así, en esta breve revisión del estado del arte no se detecta que haya tentativas de identificar las fortalezas y debilidades de cada una de las instituciones que componen la Unión Europea a efectos digitales y en relación al uso directo que cada ciudadano puede hacer de ellas. De este modo, la originalidad de esta propuesta radica en que nos situamos en el lado del ciudadano como usuario para "exigirle" a las instituciones que nos rigen mayor disposición real para conectar a cada persona con cada una de ellas. Y esto es tan fácil como trasladar los valores de la democracia participativa a la esfera digital, lo cual tiene una ejecución de tipo técnico, para cuya implementación solo se necesitan por un lado profesionales de este sector, pero sobre todo la convicción y grandes dosis de voluntad para llevarlo a cabo. 
Bajo estas premisas, el objetivo principal de este artículo es definir qué contenidos, instrumentos y funcionalidades contiene cada página que sirva realmente al objetivo principal que proclama la propia Unión en su texto de constitución: hacer más fácil la vida de los europeos (Oficina de Publicaciones de la Unión Europea, 2018).

Los objetivos secundarios de este artículo son los siguientes: $1^{\circ}$. Identificar el tono de comunicación de cada institución (tone of voice), $2^{\circ}$. Conocer el grado de usabilidad y accesibilidad de las mismas y $3^{\circ}$. Establecer una propuesta que integre las aspectos más necesarios y prácticos de cada web con el fin de mejorar la utilidad de la Unión Europea en este sentido.

Las hipótesis que planteamos son las siguientes:

H1: Las instituciones de la Unión Europea carecen de los mecanismos suficientes para dar respuesta a los ciudadanos.

H2: Las páginas web de las instituciones de la Unión Europea no tienen un espacio dedicado inequívocamente a los ciudadanos.

H3: Hay falta de unidad en la imagen de la Unión Europea y las instituciones que la forman.

El análisis de contenido será el que nos guíe a la hora de analizar y ordenar la gran cantidad de información que contienen todas estas páginas. Berelson sostiene que:

El análisis de contenido es "una técnica de investigación para la descripción objetiva, sistemática y cuantitativa del contenido manifiesto de la comunicación". Según esta definición, el análisis de contenido ha de someterse a ciertas reglas. La "objetividad" se refiere al empleo de procedimientos que puedan ser utilizados por otros investigadores de modo que los resultados obtenidos sean susceptibles de verificación (Berelson, 1952 p. 18).

No obstante, nuestro análisis está destinado a comprender la estructura de cada web y a conocer sus contenidos en relación con la utilidad que tienen para los ciudadanos europeos. Por otro lado, se ha realizado una encuesta a un grupo de ciudadanos residentes en países de la Unión Europa con la intención de recoger su percepción de manera general sobre el grupo de instituciones estudiadas. 


\section{La Unión Europea como espacio de interacción para los ciudadanos: bases del análisis}

La Unión Europea está formada 28 estados, cuya soberanía se ha puesto parcialmente en común para poder tomar decisiones sobre asuntos específicos de interés precisamente común y de manera democrática. De ahí que la labor de la Unión Europea sea, como se ha referenciado antes, "mejorar la vida de las personas en Europa y en otros lugares". Es difícil evaluar si esa intención tan general de mejorar la vida de las personas se vuelve tangible y se percibe cómo tal. De momento, como el único mecanismo abierto y de libre acceso son cada una de las webs que componen la Unión Europa, vamos a analizar una a una las que hemos anunciado, empezando por la de la propia Unión Europea.

Se explica a continuación en qué ha consistido el análisis para llevar a cabo esta investigación. En su totalidad ha sido de tipo digital, y bajo los siguientes parámetros que se han definido, todos lo cuales están disponibles en Anexo 1 (Tabla 1: Análisis páginas webs de las instituciones de la Unión Europea). En dicha tabla aparecen detallados los 13 cuerpos que componen la Unión Europea.

Se estudian en primer lugar las funcionalidades técnicas de cada web. En aras de lograr la máxima conexión con el usuario, hemos entendido después de una revisión exhaustiva que un usuario debe tener disponibles para poder comunicarse con cada institución al menos opciones como la suscripción por e-mail; que un usuario pueda recibir periódicamente un boletín de noticias del Parlamento Europeo puede parecer irrelevante, pero que exista la posibilidad en sí misma no lo es. Es un recurso más a su alcance. Lo mismo sucede con los plug-ins a redes sociales, y los feed de noticias, que deben estar disponibles porque son un reflejo del contenido principal llevados allí donde el ciudadano lo tiene a mano (su correo electrónico o sus redes sociales). Es una prueba de la intención de acercamiento real entre el ciudadano y la institución. El formulario de contacto forma parte de lo mínimo que debe una ofrecer una web para que cualquier persona pueda trasladar una consulta, pero no en todos los casos existe. Poder encontrar fácilmente las formas de contacto de manera separada respecto al formulario también es un aspecto a considerar. Que el pie de la página contenga enlaces a datos legales, a formas de contacto y sobre todo al contenido desarrollado de las diferentes secciones sin tener que desplegar nuevamente el menú, es un requisito de usabilidad y accesibilidad mínimo (Krug, 2006).

Hemos denominado la segunda sección como "Acceso a datos de interés ciudadano", que incluye los siguientes ítems de análisis: en primer lugar, es fundamental que exista una sección dedicada exclusivamente a los ciudadanos como tales y denominada con claridad, para que cada usuario como individuo 
sepa por dónde empezar a buscar información que le afecta exclusivamente a él. Lo que puede parecer una evidencia en ocasiones está lejos de serlo, de ahí que la filosofía general de la Unión Europea (facilitar la vida de las personas) se deba ver reflejada en cada espacio institucional. Por otro lado, es imprescindible encontrar una sección sobre Transparencia y Open Data.

El Open Data Institute (2020) fue fundado en 2012 por Tim Berners-Lee y el experto en inteligencia artificial Sir Nigel Shadbolt para propagar el valor del acceso abierto y libre a los datos y para abogar por el uso innovador de los datos que generen un cambio positivo para el mundo. Partimos de la filosofía de este espacio digital "People, economies and societies are not getting the best value from data" para considerar que es imprescindible una sección bajo este enfoque, para que cada persona conozca las políticas de transparencia de la página donde se encuentra y los datos que también están disponibles para él. Cada vez con más frecuencia todo tipo de webs de cualquier naturaleza publican los datos de los desarrolladores de la página y los programas y herramientas que se han usado para hacerlas. Con más razón deberíamos esperar esta información desde las entidades públicas.

Las agendas de los principales mandatarios del Parlamento Europeo, del Consejo de la Unión Europea, etc. deben ser públicas y de acceso abierto para cualquiera que desee consultarlas. La agenda en muchas ocasiones incluye la publicación de eventos, actividades y por supuesto la agenda institucional.

Que el contenido específico esté indexado por temas parece una obviedad, pero con mucha frecuencia ese contenido no es tan fácilmente localizable ni por secciones ni con el buscador; por eso se ha seleccionado este criterio, para comprobar el desarrollo de estos temas y el desglose de los mismos, pensando en ofrecerle al ciudadano las máximas facilidades para encontrar lo que necesita e interactuar desde ahí.

La complejidad de ciertos procesos se solventa cuando existen herramientas que aportan soluciones rápidas sin salir de la web. Por ejemplo, en el ámbito que estamos estudiando vamos a encontrar algunas, como un localizador de perfiles de redes sociales de todas las instituciones de la Unión Europa, un traductor, un buscador de sentencias, etc. Este tipo de recursos son una solución real para el usuario y además contribuyen a mejorar la imagen de la institución que la respalda.

El último ítem en relación a la información de interés ciudadano parece bastante indiscutible, pero como veremos no todas las webs lo consideran, hablamos de una referencia o explicación sobre la situación actual del Brexit. La tercera sección está dedicada al análisis stricto sensu, donde se han incorporado los siguientes ítems: el logotipo por un lado y la identificación del ente al que representa por otro, que son las unidades gráficas mínimas que se deben contemplar para confirmar que el usuario está exactamente donde quiere 
estar. A continuación encontramos el tone of voice o tono de comunicación como primer factor de interés, ya que es muy importante que se establezca la debida empatía e intención de diálogo con el usuario, lo cual tiene que ir acompañado de un diseño adecuado que facilite la navegación. Igualmente se debe conceder especial importancia al uso de un mensaje descriptivo de la entidad que estudiemos, para que quede totalmente clara cuál es su actividad si su propio nombre no lo explicita. En muchos casos el uso de vídeos didácticos y de infografías ayuda a comprender cierto tipo de procesos, evitando que el usuario tenga que leer.

Técnicamente, y como principios básicos de usabilidad y accesibilidad, hemos considerado los siguientes: la necesidad de un buscador, el selector de idioma, el contacto con el equipo que desarrolla la web para notificar alguna información errónea, etc. Por otro lado, se pone énfasis en el aprovechamiento de convenciones (Krug, 2006). Es fundamental utilizar todo aquello que la gente ya conoce por su experiencia como usuario en general. Por ejemplo, que haya un buscador indexado, un apartado de contacto, que se pueda compartir el contenido consultado, copiar un enlace concreto, etc., son usos que se deben mantener porque contribuyen a facilitar en gran medida la experiencia de navegación.

La accesibilidad web es cada vez menos la gran olvidada de los espacios digitales. Según la definición de W3C:

La accesibilidad Web significa que personas con algún tipo de discapacidad van a poder hacer uso de la Web. En concreto, al hablar de accesibilidad Web se está haciendo referencia a un diseño Web que va a permitir que estas personas puedan percibir, entender, navegar e interactuar con la Web, aportando a su vez contenidos. La accesibilidad Web también beneficia a otras personas, incluyendo personas de edad avanzada que han visto mermadas sus habilidades a consecuencia de la edad (Web accessibility initiative 2020).

Por otro lado, la accesibilidad web tiene una conexión directa con la igualdad, porque cuando una web es accesible puede dar acceso equitativo e igualdad de oportunidades a las personas con discapacidad, haciendo que sean partícipes activos de la sociedad, tal como refiere esta web.

\section{Ciudadanización de las instituciones: working progress}

Este apartado se dedica íntegramente a analizar las principales instituciones de la Unión Europea que se han anunciado al principio, siguiendo cada uno de los criterios establecidos, con el fin de ofrecer una visión exhaustiva del estado en el que está cada una a efectos de contenidos, funcionalidades técnicas, 
oportunidades de interacción, usabilidad y accesibilidad, etc. Se ofrece así un repaso lo más parecido posible a la experiencia de navegación que tendremos si accedemos a cada una de estas páginas.

\subsection{La Unión Europea}

La Unión Europea como ente aglutinador de catorce instituciones presenta una web sencilla y limpia, sin excesos visuales. Sirve como núcleo de inicio de todas las instituciones y ayuda a localizarlas fácilmente para empezar la navegación. Aunque pueda parecer una web de transición hacia cada una de las catorce, no debe obviar ciertos recursos que le vinculan al ciudadano. Siguiendo nuestros parámetros de análisis podemos decir que no ofrece ni suscripción a newsletter, ni el menú web completo en el pie de la página. Sí tiene un enlace a un buscador de redes sociales de todas las instituciones, no propio. Tiene formulario de contacto y publica los datos de acceso presencial, telefónicos y por correo electrónico.

Respecto a los ítems de análisis del apartado Acceso a datos de interés ciudadano, nos llama la atención la funcionalidad específica relativa al localizador de redes sociales que permite seleccionar por red y por institución, tema y tipo de cuenta (corporativa, local, personal, etc.). Puede observarse en detalle en figura 1. Es destacable también la sección por temas de interés para el ciudadano como agricultura, negocios e industria, educación, empleo, etc., en los que puede consultar información técnica, ampliar extensamente todos esos datos, etc. El problema es que el avance de la navegación va referenciando a otros enlaces que, siendo útiles, alejan al usuario del tema de interés inicialmente buscado. Para compensar esta cuestión diremos que todos los datos y documentos que se ofrecen son descargables y están escritos y diseñados de manera amena y comprensible. 


\section{Social networks \\ Interested in checking EU content on Twitter, Facebook and the rest? Use this search tool to find social media accounts with EU input.}

Select the network(s) and/or use the filter(s) below:
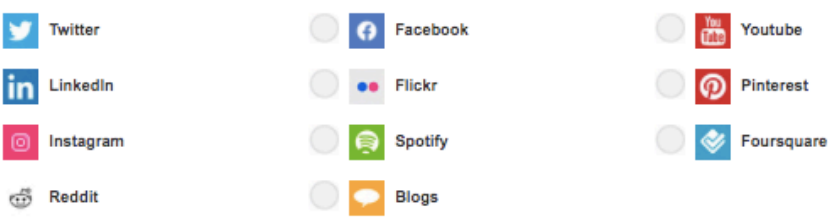

Select all | Deselect all

Filter by institution or agency:

Filter by topic:

Filter by type of account:

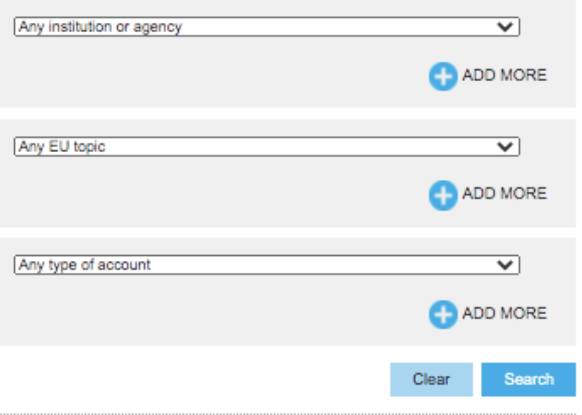

Figura 1: localizador de redes sociales.

Fuente: Unión Europea, 2020.

Normalmente, todas las webs estudiadas contienen un apartado dedicado a la transparencia y al uso de Open Data. Lo mismo sucede con el uso de datos personales, que sí existe una referencia a ellos y a las políticas de privacidad respecto a los mismos.

Hemos de decir que la publicación de la agenda de la Unión Europea no aplica aquí, porque se canaliza mediante la de cada institución. Sí existe finalmente un enlace a información sobre el Brexit, que está integrado en el menú; tiene poca visibilidad y parece más un ítem de obligada publicación.

Los ítems de contenido son aquellos que mejor nos permiten ver cómo de "ciudadanizadas" están las instituciones que estudiamos. Recursos tan obvios como que su logotipo y su nombre estén presentes y que en la dirección web se incluya el identificador .eu son fundamentales, y en todas las webs estudiadas aparece. La ausencia de un posicionamiento verbal o un claim descriptivo es notable en la mayoría de los casos, y aquí también. Hubiera sido muy diferenciador que en el espacio gráfico del logotipo se incluyera ese elemento 
descriptivo, que, lejos de lo comercial, contribuyera a ese objetivo que, sin llegar al final de la investigación, consideramos que necesita la Unión Europea. Un simple Welcome! generaría cierta conexión inicial porque una institución sería capaz de saludar a quien se acerca a ella. No solo no perjudicaría su imagen, sino que difuminaría esa visión rígida que en muchas ocasiones podemos tener de la Unión Europea.

El tratamiento que reciben los textos de la web guarda proporción entre lo cercano y directo y lo corporativo. Se usa indistintamente la segunda persona del singular y del plural para dirigirse al ciudadano, lo cual, aunque no esté unificado, al menos produce más interés que los textos informativos escritos en tono impersonal.

Además, la UE colabora con festivales de cine, exposiciones culturales, conciertos, conferencias y premios y certámenes artísticos en toda Europa.

- Descubra las actividades culturales apoyadas por la UE en su país EN 0.0

- Explore el patrimonio europeo a través de mapas interactivos con enlaces a 50 millones de obras de arte

Figura 2: ejemplo de redacción directa.

Fuente: Unión Europea, 2020.

En la sección de contacto se invita al usuario a llamar, escribir o ir a conocer la Unión Europa de manera amable y directa (Llámenos, Escríbanos, Venga a conocernos), lo cual inclina la balanza en favor del contacto fácil y directo con los ciudadanos.

De una manera global podemos decir que la tipología de imágenes, el lenguaje infográfico y el uso de vídeos didácticos brillan por su ausencia. Son aspectos que se descuidan y que impiden que el usuario se adentre en la web y navegue satisfaciendo su curiosidad o su necesidad de información de manera amena y rápida. Por eso encontramos textos que enlazan a otros y así sucesivamente hasta llegar normalmente a un PDF descargable o legible on line que concentra toda la información sobre el tema buscado. La excepción al uso de imágenes la presentan secciones como Material didáctico, que por lógica tienen que estar ilustradas y ser atractivas gráficamente porque están destinadas a niños. 


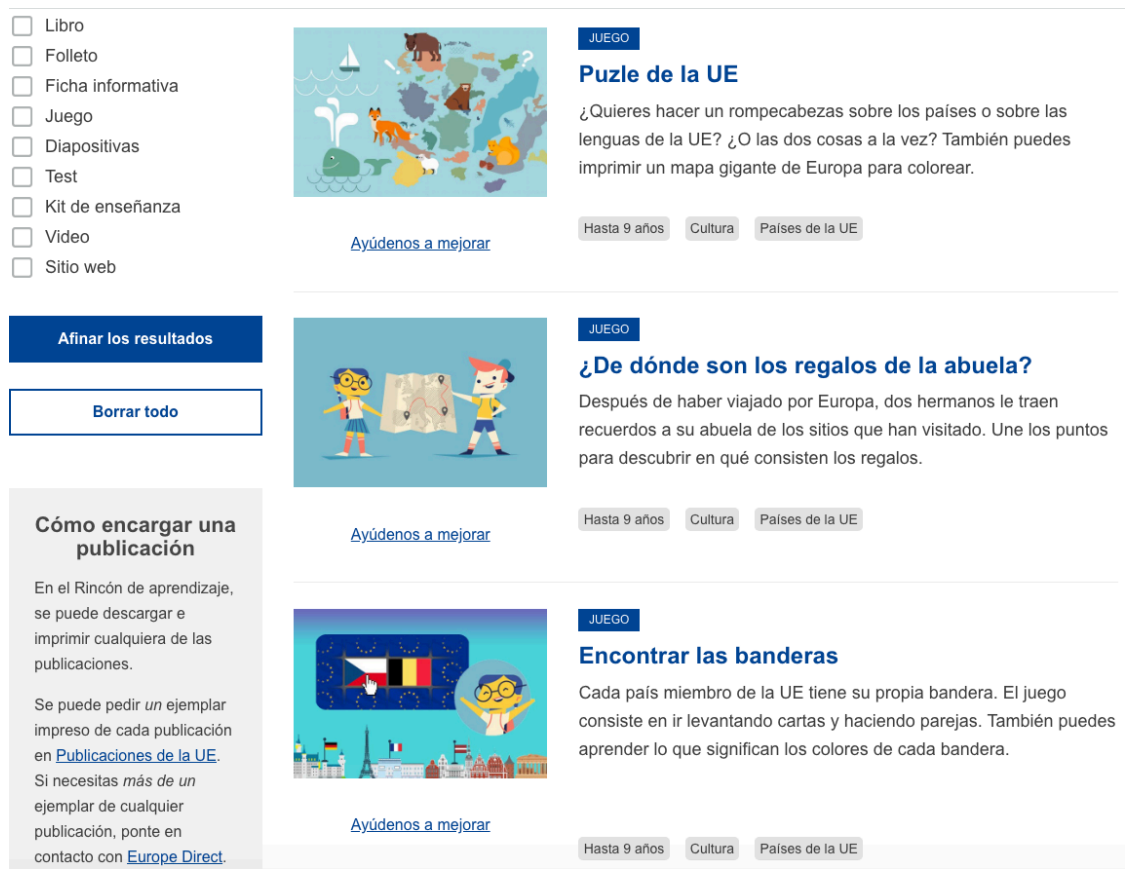

Figura 3: ejemplo de tipología de imágenes y diseño.

Fuente: Unión Europea, 2020.

Aquí son bastantes y son diversas las opciones para buscar por tipo de material (fijémonos cómo en el lado izquierdo de la página), lo cual es un tipo de filtro muy bien pensado para el área didáctica pero también lúdica en la que nos encontramos. También están disponibles vídeos dirigidos a gente joven con títulos tan directos como "Un día en la vida de...", que narra cómo es la vida de las personas en los distintos rincones de Europa o presenta vídeos sobre el programa Erasmus.

En síntesis, podemos decir que se dosifican bastante los recursos audiovisuales en función del tipo de público al que se enfoca el contenido. Una web que a primera vista parece fría, corporativa y distante resulta que contiene puzles para niños de 3 años. Observemos la Figura 4, que muestra la cabecera de la página de la Unión Europea llamada Zona de aprendizaje. La palabra Zona seguida de otra que no sea Euro, llama cuanto menos nuestra atención. Zona es este tipo de palabra que integra muy bien y de manera simpática contenidos dirigidos a jóvenes. Son numerosos los ejemplos de la comunicación comercial donde podemos localizarla. 


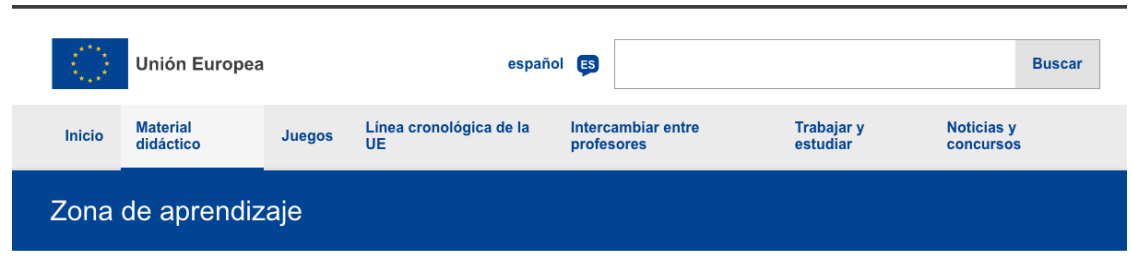

Figura 4: cabecera de sección Zona de aprendizaje.

Fuente: Unión Europea, 2020.

Los últimos aspectos del análisis de esta página están relacionados con la usabilidad y accesibilidad. La página de la Unión Europea aprovecha funcionalidades tan estandarizadas como el buscador y el selector de idioma. También mantiene fijo el menú en la parte superior según se hace scroll. Por otra parte, permite contactar con el webmaster para notificar detalladamente cualquier tipo de incidencia. De lo que adolece es de opciones de accesibilidad para usuarios discapacitados auditivos o invidentes.

\subsection{El Parlamento Europeo}

La página web del Parlamento Europeo cambia totalmente la perspectiva del usuario respecto a la anterior. Ya en la home lo primero que leemos es Stay informed (manténgase o mantente informado), apelando al usuario a estar al día sobre los que está haciendo el Parlamento, a revisar las últimas noticias o a ver los encuentros en directo, así como a seguir al Parlamento en redes.

European Parliament

News MEPs About Parliament Pienary Commitiees Delegations Other websites

\section{Stay informed}

Stay updated on what Parliament is doing. Check out the latest news, watch our meetings live and follow MEPs on social media.

Figura 5: cabecera de la home de la web del Parlamento Europeo.

Fuente: Parlamento Europeo, 2020.

Fijémonos en el tono del texto en "what Parliament is doing”, lo que está haciendo el Parlamento. Suena desenfadado, incluso coloquial. La home ya contiene una excelente infografía sobre los miembros, cuerpos y actividades del Parlamento Europeo. Más abajo hay dos apartados destacados de contenido muy práctico sobre el parlamento europeo (Learn more about the European Parliament) y, por otro lado, un grupo de Herramientas legislativas (Legislative tools) que teniendo un enfoque profesional están al alcance del ciudadano: Legislative Observatory y Legislative Train Schedule. Esta última es una 
herramienta de aspecto totalmente distinto, porque está adaptada al típico panel de salidas de una estación ferroviaria. Destaca muchísimo esta herramienta sobre las demás y sobre el look de las páginas anteriores. Si nos fijamos en el texto, tiene un tono muy positivo y optimista (A stronger Europe in the World, Promoting European Way of Life, a New Push for European Democracy, etc.).

El objetivo de esta funcionalidad que tiene una $u r l$ independiente es ofrecer una consulta fácil y rápida sobre las comisiones y propuestas comprendidas entre 2019 y 2024, y mostrar en qué fase del proceso están (han salido, están en espera, han llegado o se han descarrilado). La tercera herramienta es un Think Tank, que incorpora asimismo diversas funcionalidades como infografías, buscador, podcasts, etc. A su vez contiene documentos descargables en varios idiomas que contienen datos, indicadores, tablas de análisis, fórmulas matemáticas, etc. Es decir, un sinfín de información abierta, disponible, accesible para cualquiera que la necesite. Hay un documento llamado Mapping threats to peace and democracy worldwide. Normady Index 2020 que ilustra totalmente lo expuesto.

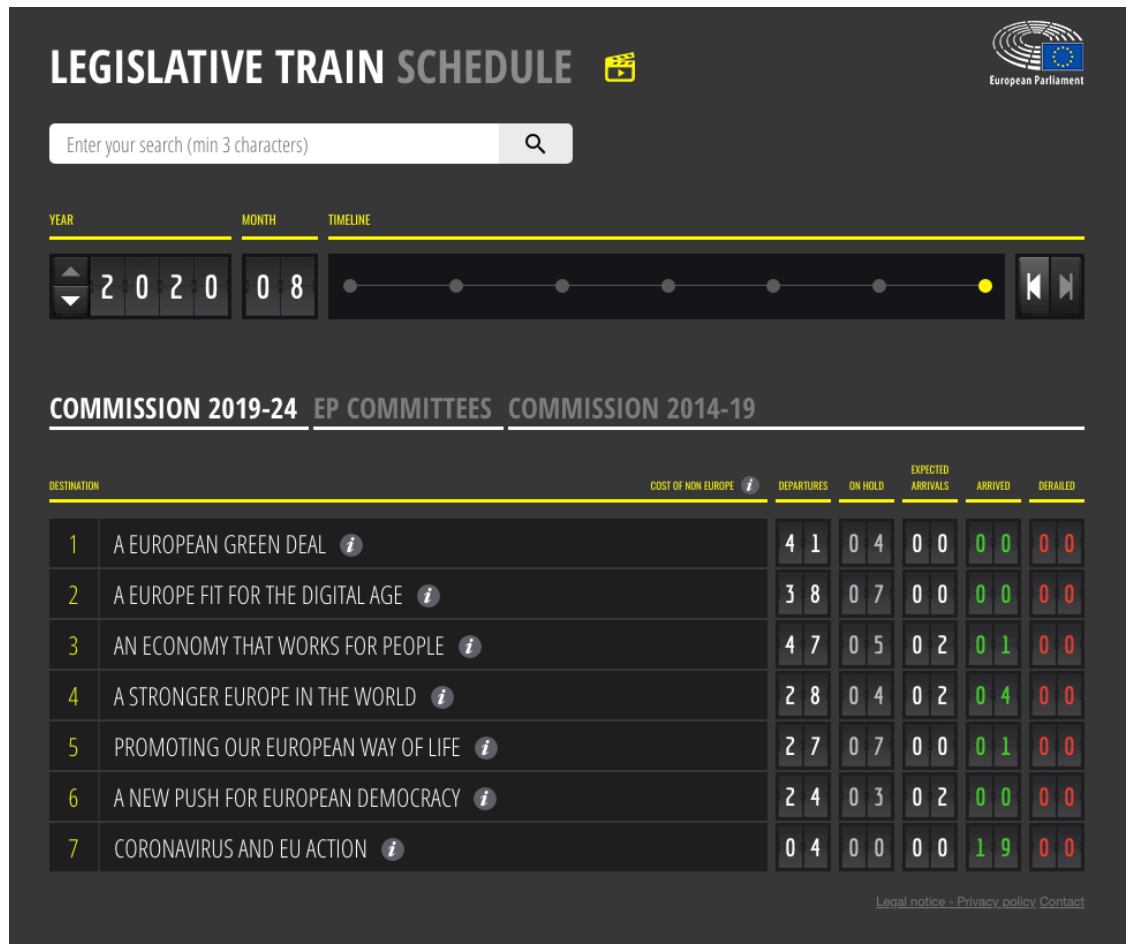

Figura 6: herramienta Legislative Train (European Parliament).

Fuente: Parlamento Europeo, 2020. 
Respecto a las funcionalidades técnicas que contiene nuestra ficha de análisis podemos decir resumidamente que la web del Parlamento Europeo tiene perfiles en redes sociales, ofrece formulario de contacto, publica datos de acceso geográfico, telefónico y mediante correo electrónico. Por otro lado, no ofrece la opción de suscripción a newsletter ni contiene el menú detallado en el pie de la página.

Dentro del apartado de análisis Acceso a datos de interés ciudadano es destacable cómo se presenta la sección Agenda. En realidad, lo hace de una manera abierta, fácil y que permite ser consultada usando filtros, incluso ser descargada por día y por tipo de evento.

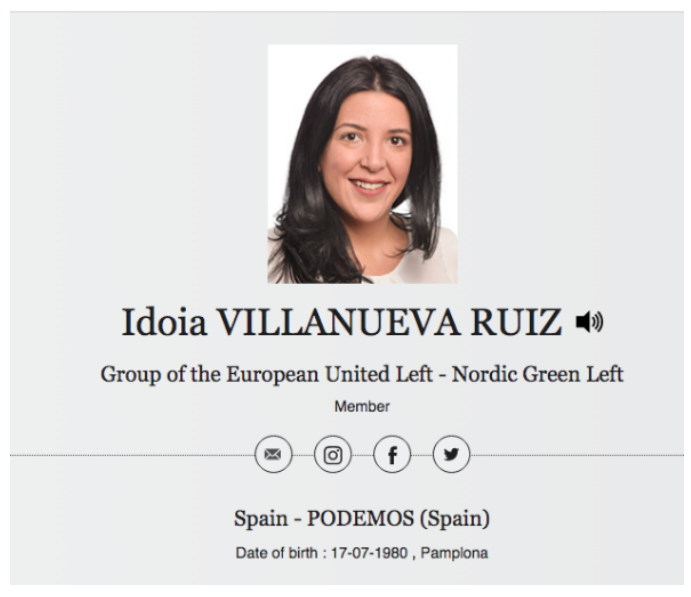

Figura 7: Imagen sección At your service

Fuente: Parlamento Europeo, 2020.

Con la misma facilidad encontramos el contenido publicado indexado por temas y existe una sección específica dedicada a la transparencia en el uso y publicación de datos. No hay referencia alguna al uso de datos personales y tampoco presenta ningún Disclaimer sobre el Brexit. Lo que sí es muy reseñable es su buscador de parlamentarios europeos mediante un mapa interactivo que muestra a cada político con sus datos de contacto (perfiles en redes y e-mail), lo cual denota una intención clara de que cualquier ciudadano pueda dirigirse de un modo directo a cualquier parlamentario europeo. Estamos por tanto ante un ejemplo muy claro de la ciudadanización del Parlamento Europeo. La figura 7 así lo muestra. 
Las cuestiones de Contenido que estudiamos en cada web resultan todas en una valoración positiva, ya que aparece claramente el logotipo del Parlamento, la web queda identificada con .eu, tiene un diseño funcional, utiliza adecuadamente el lenguaje infográfico e incorpora vídeos didácticos. Las imágenes que ilustran la web son modernas en general, pero en otros casos son demasiado obvias o sencillas, como se puede ver en la siguiente figura. Finalmente, podemos añadir que el Parlamento Europeo cumple con todos los requisitos de usabilidad y accesibilidad establecidos al principio del análisis (buscador, selector de idioma, contacto con webmaster, etc.).

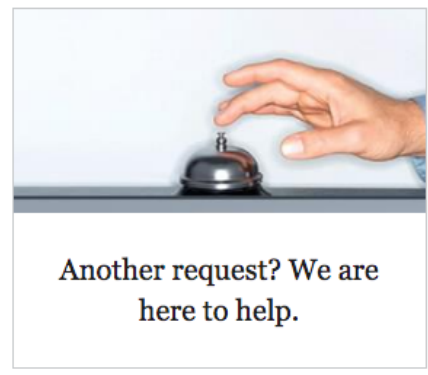

Figura 8: Imagen sección At your service

Fuente: Parlamento Europeo, 2020.

\subsection{Consejo de la Unión Europea}

De la web del Consejo de la Unión Europea se desprende en general una intención de hacer llegar la información y todos sus contenidos a los usuarios, pero en realidad no es una web muy práctica y la navegación no es muy cómoda, porque el usuario encuentra a veces un exceso de información a la vista y de ítems sobre los que hacer clic.

Las funcionalidades técnicas que hemos identificado como necesarias las tiene todas (opción de suscripción a e-mail, enlace a redes sociales, formulario de contacto y diversas formas de contacto), excepto el menú desarrollado en el pie de la página.

En cuanto al acceso a datos de interés ciudadano, es en este aspecto en el que presenta más debilidades, ya que no contiene una sección específica de interés para ello; tampoco están publicados los datos de los desarrolladores y de los programas y softwares utilizados para la creación de la web. No tiene funcionalidades destacadas y útiles para el usuario, y tampoco contiene ninguna referencia expresa al Brexit.

Los aspectos positivos son los siguientes: existe una sección sobre transparencia u Open Data, se hace mención explícita al uso de datos personales, el contenido expuesto está indexado por temas y la agenda o el Meeting Calendar en este caso es abierto y de fácil manejo. 
Mientras que hemos echado en falta contenido dirigido exclusivamente al ciudadano, en cuestión de contenido de tipo exclusivamente político podemos afirmar que estamos ante un escenario digital muy completo y estudiado en este sentido. El logotipo está acompañado de un mensaje descriptivo bajo el nombre "Council of the European Union" y la imagen general que presenta se apoya en imágenes de tipo institucional normalmente, pero también podemos encontrar ilustraciones en algún caso. Contiene por otro lado vídeos didácticos y recurre en ocasiones al uso de infografías. Nos llama la atención que exista un PDF con el desarrollo de la identidad visual del Consejo Europeo, que se implementó en 2014. Lo entendemos como un buen ejercicio de información y transparencia que vale la pena destacar.

Todos los ítems de usabilidad y accesibilidad están convenientemente trabajados en esta página excepto que el menú no se mantiene fijo en la parte superior al hacer scroll, lo cual es muy necesario para que el usuario no pierda de vista el menú mientras avanza.

\subsection{Presidencia del Consejo de la Unión Europea}

Estamos sin duda ante la mejor web de todas las estudiadas en términos generales. Ya desde la home se percibe un ambiente digital amable y empático por el tono de comunicación (Together for Europe's recovery). Es una página fácilmente navegable, clara, funcional y a la vez gráficamente elegante, respondiendo al nivel institucional que se espera de Alemania como país presidente del Consejo de la Unión Europea desde 2020.

De las funcionalidades técnicas definidas al inicio como necesarias tiene todas (feed y enlace a redes sociales, formulario de contacto, formas de contacto adecuadas), excepto que carece de la opción de suscripción a newsletter, lo cual hubiera sido deseable desde el punto de vista del ciudadano que demanda esta conexión con la Presidencia del Consejo de la Unión Europea. Tampoco aparece el menú completo en el pie de página, pero pensamos que se ha podido obviar por la intención que tiene la página de mostrase de una manera sencilla, minimalista y limpia, no por un descuido o una ausencia de obligaciones sobre la exposición de la información.

La presentación del menú obedece también a esos criterios estéticos de sencillez y minimalismo. Son muy simples y comprensibles cada uno de los ítems del menú: Programa, Noticias, Eventos, Presidencia y Prensa. Después de destacar mediante un carrusel de navegación horizontal las noticias más relevantes, figura el mensaje de bienvenida de Angela Merkel, que como canciller del país que preside el Consejo de la Unión Europa, dirige un saludo amistoso, cordial y directo a todos los europeos, presentando a Alemania como el papel que ocupa en el Consejo desde 2020. Las palabras que más utiliza son 
Together, common, challenge, que aterrizan en el siguiente mensaje final, que es del todo empático, afable, e incluso entrañable, por cómo involucra con su tono a los ciudadanos de Europa.

I am therefore glad that you are interested in Europe. I cordially invite you to find out more about the programme, events and many other aspects of Germany's Presidency of the Council of the EU on this website and on the social media channels of the German Government. Help to make Europe strong! For Europe can only succeed if we work together (Presidency of the European Union, 2020).

Merece un comentario especial el vídeo que encontramos a continuación: su mensaje, su concepto gráfico y los recursos audiovisuales que usa están concebidos con una exquisitez estética importante, está muy cuidado y ofrece un mensaje informativo muy sencillo que enlaza con el mensaje de Angela Merkel y que está orientado al trabajo de todos los ciudadanos para superar los efectos de la crisis de la covid-19. Vídeo que se puede descargar y que se está disponible en lenguaje para sordos. Sin ir mucho más lejos podemos comprobar que efectivamente los requisitos de accesibilidad que le exigimos a una web institucional los cumple.

Respecto a los demás ítems que tienen que ver con el acceso a datos de interés ciudadano, los dos únicos ítems que no hemos identificado han sido una sección específica con información útil para los ciudadanos europeos y alguna mención o referencia al Brexit. No obstante, sí existe una sección concreta sobre transparencia, podemos consultar abiertamente la agenda y encontramos el contenido indexado por temas. También existe un espacio que explica el tratamiento de los datos personales obtenidos por la navegación o registro en la página. Igualmente se nos permite consultar los datos de los desarrolladores web. Por otra parte, es muy práctica la funcionalidad integrada que presenta esta página llamada Presidency Translator, que traduce a los 23 idiomas distintos que se hablan en la Unión Europea, porque evita recurrir a traductores externos a veces de dudosa calidad.

En las cuestiones de contenido, ya se ha visto que la Presidencia del Consejo de la Unión Europea cuenta con un logotipo cuidadosamente diseñado, sobre lo cual se ofrece información detallada. Lo definen como "A strong band for a united Europe" y se acompaña de la justificación gráfica y cromática del diseño, así como del poderoso concepto de Unión que lo soporta ("The Möbius strip is the classic example of a single-sided surface in algebraic topology"), información que un usuario interesado puede agradecer igual que otras de tipo económico y político, y que tiene disponible también en vídeo. 


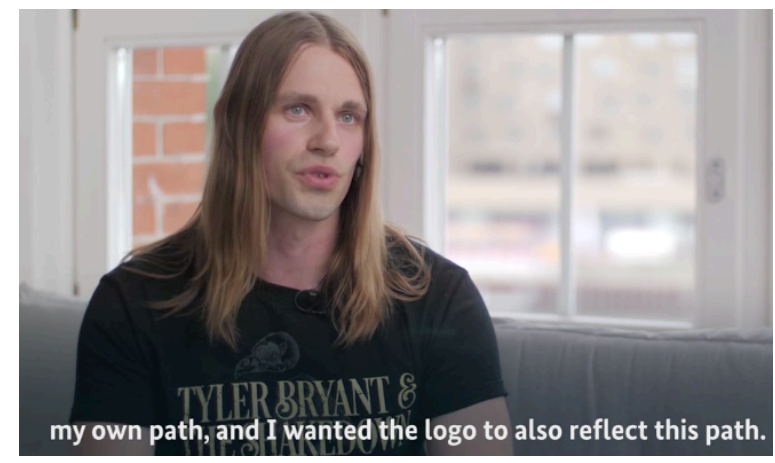

Figura 9: Vídeo explicativo sobre el diseño del logotipo Fuente: Presidencia del Consejo de la Unión Europea, 2020.

Como ya se viene observando, si se han leído los textos de la página, se percibe claramente un tono de comunicación adecuado, sencillo, respetuoso, inclusivo, plural y constructivo, que hace partícipe a cada persona que los lee. La tipología de imágenes que ilustra la página guarda un equilibrio correcto entre lo institucional, lo didáctico y lo informativo para acompañar cada contenido de manera coherente. En general podemos decir que son imágenes inspiradoras, ciertamente optimistas y positivas.

Los cinco criterios finales de nuestro análisis aplicados a usabilidad y accesibilidad como hemos ido exponiendo al navegar, los cumple sobradamente (existencia de un buscador, selector de idioma, contacto con el equipo web, aprovechamiento de convenciones digitales y facilidades de acceso para discapacitados) y por supuesto mantiene el menú fijo al hacer scroll.

\subsection{Comisión Europea}

El espacio digital que la Comisión Europea presenta una propuesta de mínimos en todos los aspectos que estamos valorando aquí. Resumidamente podemos afirmar que, aunque no tiene el servicio de suscripción a newsletter, sí tiene enlace a redes sociales, como también formulario de contacto, publica las diversas formas de contactar con la Comisión Europea (presencial, telefónica y por correo electrónico) y presenta el menú completo en el pie de la página.

Respecto al acceso a datos de interés ciudadano comprobamos que no existe una sección dedicada a ellos exclusivamente, donde un usuario en ese papel pueda identificar fácilmente un lugar específico para él. Tampoco encontramos una referencia al uso de datos personales ni es posible consultar la agenda de la Comisión; lo mismo sucede con las cuestiones relacionadas con el Brexit, que no hay mención alguna. No se ha diseñado tampoco ninguna funcionalidad ni utilidad específica en esta página. Por el contrario, sí se ha 
dispuesto información sobre transparencia, e igualmente podemos localizar bien los contenidos, ya que están indexados por temas.

Los aspectos relacionados con el contenido se quedan en un nivel medio. El tono de los textos es totalmente informativo, carentes de empatía y emoción. Las imágenes son totalmente institucionales, pero se nota que no hay criterio gráfico destinado al éxito visual de la página. No encontramos ninguna pieza de tipo infográfico ni vídeos que apoyen o ilustren de manera más amena la información expuesta.

En los apartados concernientes a usabilidad y accesibilidad también son mínimos los aspectos considerados: esta web tiene buscador, selector de idioma y permite contactar con el webmaster. Por el contrario, ni aprovecha las convenciones de navegación, ni mucho menos facilita el acceso a la información a discapacitados auditivos o invidentes.

\subsection{Corte de Justicia de la Unión Europea}

Esta web ofrece un aspecto radicalmente distinto respecto a todas las anteriores. La ausencia del característico color azul llama la atención desde el principio. Corporativamente sus colores son el rojizo, el dorado y el gris y los utilizan tanto en home como en páginas interiores.

Respecto a las principales funcionalidades técnicas estudiadas, aquí sucede como en la web anterior; sí podemos seguir a la Corte de Justicia Europea en sus redes, sí podemos contactar con ellos mediante un formulario, así como por vía postal, telefónica y mediante correo electrónico. Por el contrario, no hay opción de suscripción a newsletter ni podemos encontrar la totalidad del menú en el pie de la página.

Los únicos recursos destacables en cuestión de acceso a datos de interés ciudadano son el buscador de sentencias y el calendario judicial. También está disponible la agenda de la Corte de Justicia. Esos son los aspectos más positivos. En otro sentido, carece totalmente de apartados o secciones pensadas para resolver cuestiones útiles para la ciudadanía, de una sección sobre transparencia y de referencia alguna al Brexit. Tampoco el contenido ha sido indexado por temas para facilitar su localización. Del mismo modo no se permite notificar ningún fallo a los desarrolladores de la web.

Unos minutos de navegación bastan para ver que el tono de los mensajes es informativo con predominio institucional. Las imágenes que apoyan los textos son escasas, apenas son tres las que encontramos en toda la web. En los interiores, al estar en un ámbito totalmente jurídico, toda la información publicada es escrita, por lo que tampoco hay ni vídeos y mucho menos infografías, si bien esto no tiene una consideración especialmente negativa. 
La presencia de un buscador y el selector de idioma son los dos aspectos que mejoran la usabilidad de esta página. Las demás funciones requeridas no se encuentran: contacto con el equipo web, menú fijo al hacer scroll, aprovechamiento de convenciones y lectura para discapacitados.

\subsection{Banco Central Europeo}

Si bien desde la home parece que estamos ante una página ordenada y sencilla, no lo es tanto. Sin ir más lejos, y de manera demasiado discreta, encontramos una sección llamada

"Our response to the coronavirus pandemic", que lleva a una página interior, con un nuevo menú, en lugar de estar integrado en el principal. Nos hace pensar que ha sido la urgencia de los acontecimientos lo que conduce a tomar decisiones así.

En general estamos ante una web muy compleja, con demasiados niveles y subniveles de información, no hay más que hacer clic en el cada uno de los nueve ítems del menú principal para percibir esta complejidad en la disposición de la información. Hay grupos de contenidos que se presentan en botones como estos que recogemos en la Figura 10 y que distraen en cuando a la presentación de la información respecto a cómo se hace globalmente en la página. Entre unos y otros se ubican gráficos de tasas de interés, tasas de inflación, etc. En general crea cierta confusión esta profusión de datos en cascada.

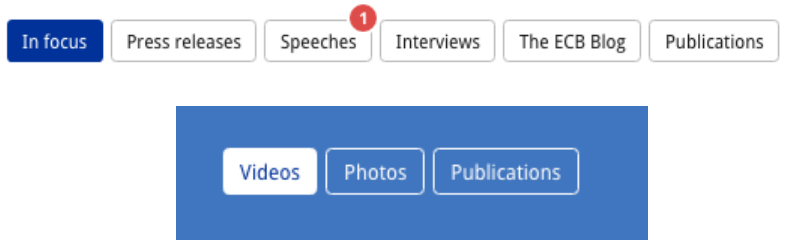

Figura 10: Botones

Fuente: Banco Central Europeo, 2020.

Lejos de cumplir con las funcionalidades técnicas que hemos definido como necesarias, la web del Parlamento Europeo no permite suscribirse a ninguna lista de correo, tampoco tiene formulario de contacto directo, solo publica su dirección postal, sus números de teléfono y su correo electrónico. En el pie de la página no figura el menú de la web completa.

Respecto a los datos de interés para el ciudadano solo encontramos la referencia a datos personales y la agenda. No sucede lo mismo en el caso de la sección que esperamos en relación a los ciudadanos, a la transparencia, a que 
el contenido esté indexado por temas, etc. Tampoco existe manera de contactar con los desarrolladores de la página, no dispone de ninguna funcionalidad específica y tampoco se identifica referencia alguna a la cuestión del Brexit.

Las cuestiones de contenido mejoran sensiblemente, ya que tanto las imágenes como los textos están bien trabajados, el tono es directo, se apela a conocer más, a leer más con un lenguaje sencillo. Las imágenes que lo ilustran son de naturaleza mixta (institucionales por un lado y de tipo tecnológico por otro). Las primeras giran en siempre en torno a la figura de Christine Lagarde. Aun así, como se viene observando, el diseño es ciertamente antiguo. En ocasiones es difícil emitir un juicio global sobre la calidad de la página; cuando eso sucede podemos aventurarnos a decir que la página no está planteada ni realizada correctamente, sino que es producto de la necesidad de colocar cantidades ingentes de contenido a toda velocidad.

Como era de esperar, sí tiene un buscador y selector de idioma, pero no presenta ninguna facilidad para contactar con el equipo de la web, no facilita la lectura a discapacitados, no aprovecha las convenciones $\mathrm{y}$, como hemos comprobado al principio, no mantiene fijo el menú al hacer scroll.

\section{Valoración de los ciudadanos europeos sobre sus instituciones a partir de encuesta realizada}

Los ciudadanos europeos conforman esa otra parte de la esfera europea que estamos estudiando, así que les hemos hecho dos sencillas preguntas, que aun sabiendo que científicamente no son relevantes, al menos nos dan una aproximación somera del grado de conocimiento que tienen sobre las instituciones que componen la Unión Europea. La ficha técnica de esta encuesta es la siguiente:

Universo: ciudadanos de la Unión Europea mayores de 18 años (448.000.000 millones).

Tamaño muestral: 104

Metodología: cuestionario online distribuido aleatoriamente.

Fechas de trabajo de campo: del 28 de agosto al 10 de septiembre de 2020.

Duración del cuestionario: 2 minutos.

Error muestral: 9,61\% para un nivel de confianza (NC) del 95\%. 


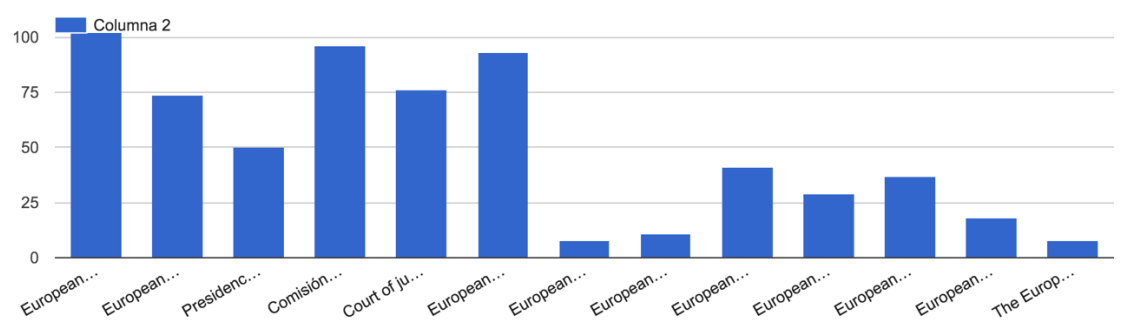

Figura 11. Pregunta 1 de la encuesta realizada.

Fuente: elaboración propia (2020)

La primera pregunta es relativa a cuántas instituciones de la Unión Europea conocen. De todas ellas, 102 de 104 encuestados ha respondido que el Parlamento Europeo. En segundo lugar, está la Comisión Europea, con 96 respuestas y en tercer lugar el Banco Central Europeo, que han marcado 93 usuarios. En las siguientes posiciones encontramos la Corte de Justicia de la Unión Europa, con 76 respuestas, seguida del Consejo Europeo, con 74 y de la Presidencia del Consejo de la Unión Europea con 50. El gráfico nos muestra cómo el resto de instituciones tienen un grado de conocimiento mucho menor.

Pensamos que la influencia de los medios se ve reflejada en respuestas como esta, porque con más frecuencia escuchamos o leemos noticias relacionadas con el Banco Central Europeo que por ejemplo con la Corte Europea de Auditores.

Please choose what have you checked any of the previous European institutions for.

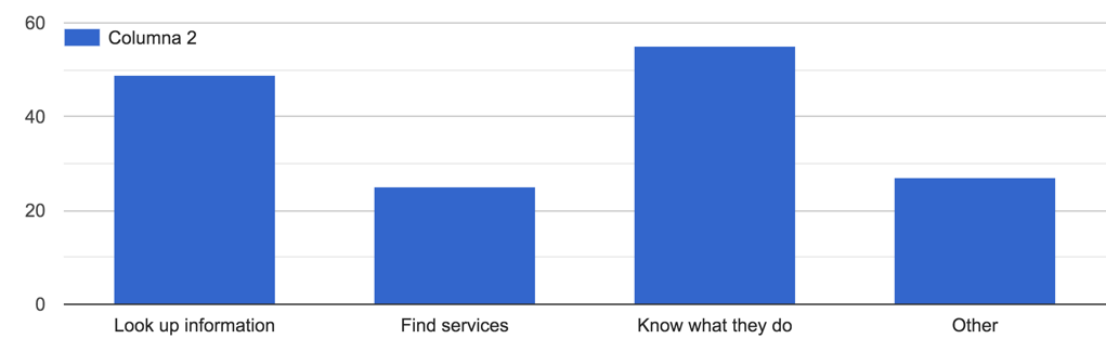

Figura 12. Pregunta 2 de la encuesta realizada.

Fuente: elaboración propia (2020) 
Saber exactamente qué funciones o qué hace cada institución es una inquietud que tienen 55 de los 104 que han respondido la encuesta, seguida de 49 personas que han marcado la opción buscar información. Buscar servicios tiene menor demanda según parece, ya que solo el 24\% tienen esta necesidad. En "Otros" se incluyen todas las demás necesidades de información que de manera general podemos tener como ciudadanos europeos.

\section{Conclusiones: la ciudadanización de las instituciones europeas es posible}

Llegados a este punto, nuestra visión de las instituciones europeas ha variado sustancialmente. Impresiones y percepciones que teníamos en nuestro papel de ciudadanos han cambiado cuando hemos ido desarrollando cada epígrafe. De modo que, analizando el grado de cumplimiento de los objetivos planteados al inicio de esta investigación, podemos afirmar que:

Se ha cumplido el objetivo principal, relativo a la exposición de contenidos, instrumentos y funcionalidades que contiene la página de cada institución de la Unión Europea y que sirva para hacer más fácil la vida de los europeos. Aunque hemos recogido estos aspectos, estamos en condiciones de afirmar que las webs que sí hacen más fácil la vida de los europeos son sobre todo la del Parlamento Europeo, la de la Presidencia de la Unión Europea y la del Board Europeo de Protección de Datos. Las demás tienen algunos recursos y funcionalidades que ayudan a agilizar búsquedas, a filtrar datos, etc., pero carecen del tono adecuado, de la usabilidad necesaria y de un planteamiento suficientemente intuitivo en su navegación.

Damos cuenta a continuación del grado de cumplimiento de los objetivos secundarios:

$1^{\circ}$. Identificar el tono de comunicación de cada institución (tone of voice): habiendo realizado este ejercicio, podemos comprobar que en general estamos ante un tono más cerca de lo empático que de lo corporativo a la hora de apelar al ciudadano. Destaca, como en otros muchos aspectos estudiados, el uso que hace del lenguaje la Presidencia del Consejo de la Unión Europea, el del Parlamento Europeo y el del Banco Central Europeo.

$2^{\circ}$. Conocer el grado de usabilidad y accesibilidad de las mismas: se ha dedicado un apartado exclusivamente a esto, de lo que se concluye que la gran asignatura pendiente de la mayoría de las instituciones estudiadas es la accesibilidad web. Solo el Parlamento Europeo y el Comité Social y Económico Europeo la trabajan, lo cual dice muy poco en su favor. Respecto a este asunto, volvemos a concluir que las páginas más usables son las mismas que las del apartado anterior y que vienen repitiéndose a lo largo de todo el artículo 
(Presidencia del Consejo de la Unión Europea, el del Parlamento Europeo y el del Banco Central Europeo).

$3^{\circ}$. Presentar una propuesta que integre las aspectos más necesarios y prácticos de cada web con el fin de mejorar la utilidad de la Unión Europea en este sentido. Si bien este objetivo es demasiado ambicioso porque exige un trabajo de consultoría web institución a institución, y supera las expectativas de este artículo, creemos que humildemente hemos aportado todos los ítems que al menos debe contener una web pública institucional mediante cada uno de los parámetros de análisis presentados en el epígrafe segundo. Sin embargo, el hecho de que no exista o al menos no de manera digital un organismo que centralice y defina con orden los contenidos mínimos, funcionalidades, usabilidad y accesibilidad que tiene que tener la web de una institución pública europea afecta negativamente a este proceso. No es suficiente con que las páginas tengan un logotipo y una extensión .eu, un buscador y un selector de idioma para pensar que son el tipo de web que un ciudadano espera. Con independencia de que un ciudadano la espere o no, las exigencias en cuanto al nivel deben partir de la propia institución.

Las hipótesis que planteamos fueron las siguientes:

H1: Las instituciones de la Unión Europea carecen de los mecanismos suficientes para dar respuesta a los ciudadanos. Por todo lo expuesto, esta hipótesis se verifica negativamente: las instituciones de la Unión Europea sí tienen mecanismos suficientes para ello. La cuestión está en que falta un organismo rector que establezca como mínimos algunos canales de interactuación, más allá del e-mail y las redes sociales. La resolución de gestiones administrativas en tiempo real debería ser una de ellas, integrando diversos canales de comunicación para una misma problemática. Como hemos comprobado, sí existen los recursos, la estructura digital y los conocimientos técnicos para hacerlo posible.

H2: Las páginas web de las instituciones de la Unión Europea no tienen un espacio dedicado inequívocamente a los ciudadanos. Esta hipótesis se verifica positivamente, ya que excepto la web de la Unión Europea como contenedora o guía hacia todas las demás, y el EDPB (European Data Protection Board), ninguna de las restantes tiene una sección específica con este nombre. Esto representa una contradicción respecto a la intención general que proclama la propia Unión Europea de hacer más fácil la vida de los ciudadanos. Se necesitan espacios digitales donde cada persona que visita la web entienda que "ese es su lugar y que eso es lo que estaba buscando". Solo así, se logrará ese acercamiento y aumentará la sensación de pertenencia al tipo de espacios que hemos estudiado, que en este caso trasciende el universo virtual para pasar a un escenario social, tangible y cotidiano. 
H3: Hay falta de unidad en la imagen de la Unión Europea y las instituciones que la forman. Esta última hipótesis la verificamos positivamente. Como hemos indicado a lo largo del texto, no es suficiente con el uso de azules y blancos de fondo en la mayoría de las páginas. Hace falta unificar la imagen con criterios gráficos estandarizados y unánimes, definiendo tipología de imagen para cada texto (foto, ilustración, icono, etc.), estilo en el uso de recursos infográficos. Por otro lado, se necesitan unas guidelines o pautas referidas a los textos; hemos encontrado bastante desorden en este sentido, producto de la falta de planificación a la hora de abordar la redacción de los mismos, sobre todo, en textos de introducción y presentación de apartados. Sabemos que los textos basados en lenguaje jurídico o económico, por ejemplo, no necesitan tanto este tipo de pautas.

La experiencia de navegación también condiciona la imagen de conjunto de las webs estudiadas. Aquí debería haber unos criterios de diseño y navegación establecidos, como que el menú se mantenga fijo al hacer scroll, que no se tenga que hacer roll-over para descubrir los contenidos, que todas las acciones se resuelvan con el menor número de clics posibles, etc. Aquí hay infinitas posibilidades de mejora. Hasta la fecha, la web que mejor recoge todas estas pautas de actuación es la de la Presidencia del Consejo de la Unión Europea.

Por todo lo cual, la ciudadanización de las instituciones europeas está en progreso. Sí existen diferencias notables entre unas y otras, pero el camino y la intención están definidos hacia la creación de un espacio de interacción común. Dado que el espíritu de participación pública y libre, de apertura e intercambio cultural son intrínsecos a los valores de la Unión Europea desde su fundación, consideramos que si las instituciones efectivamente se ciudadanizan de verdad estarán contribuyendo de manera directa a hacer ciudadanos más libres, más informados, incluso con mayor sentido de pertenencia a un espacio geográfico para pasar a ser un espacio además humano. Es imprescindible para ello que se fortalezcan los vínculos de los tres actores principales de este escenario (ciudadano-país-Unión Europea) y que se empodere sobre todo a los ciudadanos mediante herramientas para elevar sus iniciativas locales a un nivel superior, dotando de recursos a las administraciones para implementarlos y sobre todo en este caso, a la Unión Europea para trazar una línea irrompible que una los tres elementos de esta ecuación de manera duradera, consensuada y fructífera. 


\section{Referencias bibliográficas:}

BANCO CENTRAL EUROPEO (2020) [en línea] https://www.ecb.europa.eu/ home/html/index.en.html [consultado el 29 de junio de 2020]

BANCO EUROPEO DE INVERSIONES (EIB) (2020) [en línea] https://www. eib.org/en/index.htm [consultado el 21 de julio de 2020]

Berelson, B. (1952). Content Analysis in Comunication Research, Free Press, Glencoe.

COMISIÓN EUROPEA (2020) "La Unión Europea. ¿Qué es y qué hace? Oficina de Publicaciones de la Unión Europea, (2018). doi:10.2775/154459 COMISIÓN EUROPEA (2020) [en línea] https://ec.europa.eu/info/index_en [consultado el 24 de junio de 2020]

COMITÉ EUROPEO DE LAS REGIONES (CoR) (2020) [en línea] https:// cor.europa.eu/en/ [consultado el 17 de julio de 2020]

COMITÉ SOCIAL Y ECONÓMICO EUROPEO (EESC) (2020) [en línea] https://www.eesc.europa.eu/en [consultado el 15 de julio de 2020]

CONSEJO DE LA UNIÓN EUROPEA (2020) [en línea] https://www. consilium.europa.eu/en/european-council/ [consultado el 2 de julio de 2020]

CONSEJO EUROPE DE PROTECCIÓN DE DATOS (EDPB) (2020) [en línea] https://edpb.europa.eu/edpb_en [consultado el 29 de julio de 2020]

CORTE DE JUSTICIA DE LA UNIÓN EUROPEA (2020) [en línea] https:// curia.europa.eu/jcms/jcms/j_6/en/ [consultado el 27 de junio de 2020]

CORTE EUROPEA DE AUDITORES (2020) [en línea] https://www.eca. europa.eu/en/Pages/ecadefault.aspx [consultado el 11 de julio de 2020]

Friedmann, R. y Llorens, M. (2000), Ciudadanización y empowerment: formas alternativas de participación ciudadana local. "Cuadernos de análisis" (4). Recuperado a partir de http://habitat.aq.upm.es/boletin/n19/arfri.html. ISSN: 1578-097X

Gozálvez, V. (2011). Educación para la ciudadanía democrática en la cultura digital. "Revista Comunicar", (36), 131-138. Recuperado a partir de https:/www.revistacomunicar.com/index.php?contenido=detalles\&nume ro=36\&articulo=36-2011-16. ISSN: 1134-3478; DOI:10.3916/C36-201103-04

Krug, S. No me hagas pensar. Una aproximación a la usabilidad en la web. Madrid: Pearson Educación, 2006.

OPEN DATA INSITUTE [en línea] https://theodi.org/ [consultado el 2 de agosto de 2020]

PARLAMENTO EUROPEO (2020) [en línea] https://www.europarl.europa. eu/portal/en [consultado el 29 de junio de 2020] 
PRESIDENCIA DEL CONSEJO DE LA UNIÓN EUROPEA (2020) [en línea] https://www.eu2020.de/eu2020-en [consultado el 24 de junio de 2020]

SERVICIO DE ACCIÓN EXTERNA DE LA UNIÓN EUROPEA (2020) [en línea] https://eeas.europa.eu/headquarters/headquarters-homepage_en [consultado el 12 de julio de 2020]

Sierra, F. (2012) Ciudadanía digital y sociedad de la información en la unión europea. Un análisis crítico. "Andamios" (19) pp. 259-282. Recuperado a partir de http://www.scielo.org.mx/scielo.php?script=sci_arttext\&pid $=$ S1870-00632012000200012

SUPERVISOR DE DATOS EUROPEOS (EDPS) (2020) [en línea] https:// edps.europa.eu/edps-homepage en?lang=en [consultado el 24 de julio de 2020]

Torres Gastelú, C. A., Cordero-Guzmán, D. M., Soto Ortiz, J. L., \& Mory A1varado, A. (2019). Influencia de factores sobre la manifestación de la ciudadanía digital. "Revista Prisma Social", (26), 27-49. Recuperado a partir de https://revistaprismasocial.es/article/view/3099

UNIÓN EUROPEA (2020) [en línea] hhttps://europa.eu/european-union/ index_en [consultado el 20 de junio de 2020] 


\section{Anexos}

Tabla 1: Análisis páginas webs de las instituciones de la Unión Europea.

\begin{tabular}{|c|c|c|c|c|c|c|}
\hline \multirow[b]{2}{*}{ INSTITUCION } & \multirow[b]{2}{*}{ url } & \multicolumn{4}{|c|}{ FUNCIONALIDADES TÉCNICAS } & \multirow[b]{2}{*}{\begin{tabular}{|l|} 
Pie de \\
páginal \\
Menú \\
web
\end{tabular}} \\
\hline & & Suscripción email & Feed RRSS & Formulario de contacto & \begin{tabular}{|l|} 
Formas de \\
contacto
\end{tabular} & \\
\hline $\begin{array}{l}\text { EUROPEAN } \\
\text { UNION }\end{array}$ & \begin{tabular}{|l|} 
https://europa.eu/euro \\
pean-union/index en
\end{tabular} & NO & si & si & \begin{tabular}{|l|} 
Presencial, \\
teléfono, \\
email
\end{tabular} & NO \\
\hline \begin{tabular}{|l} 
European \\
Parliament
\end{tabular} & $\begin{array}{l}\text { https://www.europarl.e } \\
\text { uropa.eu/portalien }\end{array}$ & NO & si & sí & $\begin{array}{l}\text { Presencial, } \\
\text { teléfono, } \\
\text { email }\end{array}$ & NO \\
\hline \begin{tabular}{|l|} 
European Council \\
/Council of the \\
European Union
\end{tabular} & $\begin{array}{l}\text { https:/fwww.consilium. } \\
\text { europa.eu/en/europea } \\
\underline{n-c o u n c i l}\end{array}$ & $\overline{\text { si }}$ & si & si & $\begin{array}{l}\text { Presencial, } \\
\text { teléfono, } \\
\text { email }\end{array}$ & NO \\
\hline $\begin{array}{l}\text { Presidency of the } \\
\text { Council of the EU }\end{array}$ & $\begin{array}{l}\text { https://www.eu2020.d } \\
\text { e/eu2020-en }\end{array}$ & $\overline{N O}$ & si & si & $\begin{array}{l}\text { Formulario } \\
\text { web }\end{array}$ & NO \\
\hline \begin{tabular}{|l} 
European \\
Commission
\end{tabular} & $\begin{array}{l}\text { https://ec.europa.eu/in } \\
\text { folindex en }\end{array}$ & $\overline{N O}$ & si & si & $\begin{array}{l}\text { Presencial, } \\
\text { teléfono, } \\
\text { email }\end{array}$ & Sí \\
\hline $\begin{array}{l}\text { Court of justice of } \\
\text { the European } \\
\text { Union }\end{array}$ & $\begin{array}{l}\text { hittps://curia.europa.e } \\
\text { uficms/icms/i 6/en/ }\end{array}$ & $\overline{N O}$ & si & sí & \begin{tabular}{|l} 
Postal, \\
teléfono, \\
email
\end{tabular} & NO \\
\hline \begin{tabular}{|l|} 
European Central \\
Bank
\end{tabular} & $\begin{array}{l}\text { https://www.ecb.europ } \\
\text { a.eu/home/htmlindex. } \\
\text { en.htm! }\end{array}$ & $\overline{N O}$ & si & NO & \begin{tabular}{|l} 
Postal, \\
teléfono, \\
email
\end{tabular} & NO \\
\hline $\begin{array}{l}\text { European Court } \\
\text { of Auditors }\end{array}$ & $\begin{array}{l}\text { https://www.eca.europ } \\
\text { a.eu/en/Pages/ecadef } \\
\text { ault.aspx }\end{array}$ & $\overline{\text { si }}$ & si & si & \begin{tabular}{|l|}
$\begin{array}{l}\text { Presencial y } \\
\text { formulario } \\
\text { web }\end{array}$ \\
\end{tabular} & NO \\
\hline $\begin{array}{l}\text { European Union } \\
\text { External Action } \\
\text { Service } \\
\end{array}$ & \begin{tabular}{|l|} 
https:/fleeas.europa.e \\
u/headquarters/heada \\
uarters-homepage en \\
\end{tabular} & sí & sí & NO & \begin{tabular}{|l} 
Postal, \\
teléfono, \\
email
\end{tabular} & si \\
\hline \begin{tabular}{|l|} 
European \\
Economic and \\
Social Committee \\
(EESC)
\end{tabular} & $\begin{array}{l}\text { hitps://www.eesc.euro } \\
\text { pa.eu/en }\end{array}$ & NO & si & NO & $\begin{array}{l}\text { Postal, } \\
\text { teléfono. }\end{array}$ & si \\
\hline \begin{tabular}{|l|} 
European \\
Committee of the \\
Regions (CoR) \\
\end{tabular} & $\begin{array}{l}\text { https://cor.europa.eul } \\
\text { env' }\end{array}$ & $\overline{N O}$ & si & si & $\begin{array}{l}\text { Presencial y } \\
\text { formulario } \\
\text { web }\end{array}$ & si \\
\hline \begin{tabular}{|l|} 
European \\
Investment Bank \\
(EIB)
\end{tabular} & \begin{tabular}{|l|} 
https://www.eib.orgien \\
lindex.htm
\end{tabular} & $\overline{\text { si }}$ & si & si & $\begin{array}{l}\text { Presencial, } \\
\text { teléfono, } \\
\text { email y } \\
\text { formulario } \\
\text { web } \\
\end{array}$ & NO \\
\hline $\begin{array}{l}\text { European Data } \\
\text { Protector } \\
\text { Supervisor } \\
\text { (EDPS) }\end{array}$ & $\begin{array}{l}\frac{\text { https://edps.europa.e }}{\text { u/edps-homepage en }} \\
\text { ?/lang=en }\end{array}$ & NO & si & si & \begin{tabular}{|l} 
Postal, \\
teléfono, \\
email
\end{tabular} & NO \\
\hline \begin{tabular}{|l|} 
The European \\
Data Protection \\
Board (EDPB)
\end{tabular} & \begin{tabular}{|l|} 
https://edpb.europa.e \\
ufedob en
\end{tabular} & NO & NO & NO & \begin{tabular}{|l} 
Postal, \\
teléfono, \\
email
\end{tabular} & si \\
\hline
\end{tabular}




\begin{tabular}{|c|c|c|c|c|c|c|c|c|c|}
\hline \multirow[b]{2}{*}{ INSTITUCIÓN } & \multirow[b]{2}{*}{ url } & \multicolumn{8}{|c|}{ ACCESO A DATOS DE INTERÉS CIUDADANO } \\
\hline & & \begin{tabular}{l|} 
Sección \\
Ciudada \\
nos
\end{tabular} & \begin{tabular}{|l|} 
Sección \\
Transparen \\
cia / Open \\
Data
\end{tabular} & \begin{tabular}{|l|} 
Datos \\
desarrolladores y \\
herramientas \\
web
\end{tabular} & \begin{tabular}{|l|} 
Referencia \\
al uso de \\
datos \\
personales
\end{tabular} & Agenda & \begin{tabular}{|l|} 
Contenido \\
indexado \\
por temas
\end{tabular} & \begin{tabular}{|l|} 
Funcionalidade \\
s especificas
\end{tabular} & \begin{tabular}{|l} 
Referencia \\
0 \\
Disclaimer \\
sobre el \\
Brexit \\
\end{tabular} \\
\hline $\begin{array}{l}\text { EUROPEAN } \\
\text { UNION }\end{array}$ & $\mid \begin{array}{l}\text { https://europa.eu/euro } \\
\text { pean-unionindex en }\end{array}$ & $\mathrm{Si}$ & Si & NO & Si & N/A & Si & \begin{tabular}{|l|} 
Localizador de \\
redes sociales de \\
todas las \\
inctituriones a
\end{tabular} & Si \\
\hline $\begin{array}{l}\text { European } \\
\text { Parliament }\end{array}$ & $\begin{array}{l}\text { hittps://www.europarl.e } \\
\text { uropa.eu/portalien }\end{array}$ & NO & Si & NO & NO & Si & Si & \begin{tabular}{|l|} 
Buscador de \\
politicos de la \\
Unión Europea.
\end{tabular} & NO \\
\hline $\begin{array}{l}\text { European Council } \\
\text { / Council of the } \\
\text { European Union }\end{array}$ & $\begin{array}{l}\text { https://www.consilium. } \\
\text { europa.eu/en/europea } \\
\text { n-council }\end{array}$ & NO & Si & NO & Si & Si & Si & NO & NO \\
\hline $\begin{array}{l}\text { Presidency of the } \\
\text { Council of the EU }\end{array}$ & $\begin{array}{l}\text { https://www.eu2020.d } \\
\text { eleu2020-en }\end{array}$ & NO & Si & Si & Si & Si & Si & $\begin{array}{l}\text { Presidency } \\
\text { translator }\end{array}$ & NO \\
\hline $\begin{array}{l}\text { European } \\
\text { Commission }\end{array}$ & \begin{tabular}{|l|} 
https://ec.europa.eu/in \\
folindex en
\end{tabular} & NO & Si & Sí & NO & NO & Si & NO & NO \\
\hline $\begin{array}{l}\text { Court of justice of } \\
\text { the European } \\
\text { Union }\end{array}$ & $\begin{array}{l}\text { hittps://curia.europa.e } \\
\text { uficms/icms/i G/en/ }\end{array}$ & NO & NO & NO & Si & Si & NO & $\begin{array}{l}\text { Buscador de } \\
\text { sentencias y } \\
\text { Calendario } \\
\text { Judicial }\end{array}$ & NO \\
\hline $\begin{array}{l}\text { European Central } \\
\text { Bank }\end{array}$ & $\begin{array}{l}\text { hittps://www.ecb.europ } \\
\text { a.eu/home/htmVindex. } \\
\text { en.htm! }\end{array}$ & NO & NO & NO & Sí & Si & NO & NO & NO \\
\hline $\begin{array}{l}\text { European Court } \\
\text { of Auditors }\end{array}$ & $\begin{array}{l}\text { https://www.eca.europ } \\
\text { a.eu/en/Pagesfocadef } \\
\text { ault.aspx }\end{array}$ & NO & Si & NO & Sí & NO & NO & $\begin{array}{l}\text { Buscador de } \\
\text { publicaciones }\end{array}$ & NO \\
\hline $\begin{array}{l}\text { European Union } \\
\text { External Action } \\
\text { Service }\end{array}$ & \begin{tabular}{|l|} 
https:/ieeas.europa.e \\
u/headquarters/headq \\
uarters-homepage en \\
\end{tabular} & NO & Si & NO & Si & NO & Si & $\begin{array}{l}\text { Buscador de } \\
\text { contactos }\end{array}$ & NO \\
\hline $\begin{array}{l}\text { European } \\
\text { Economic and } \\
\text { Social Committee } \\
\text { (EESC) }\end{array}$ & $\begin{array}{l}\text { https://www.eesc.euro } \\
\text { pa.eu/en }\end{array}$ & NO & sí & NO & Si & sí & Si & $\begin{array}{l}\text { Buscador de } \\
\text { documentos. } \\
\text { Buscador de } \\
\text { opiniones. Ask } \\
\text { the president. }\end{array}$ & NO \\
\hline $\begin{array}{l}\text { European } \\
\text { Committee of the } \\
\text { Regions (CoR) }\end{array}$ & $\begin{array}{l}\text { hittps://cor.europa.eul } \\
\text { end }\end{array}$ & NO & NO & NO & Si & NO & Si & NO & NO \\
\hline $\begin{array}{l}\text { European } \\
\text { Investment Bank } \\
\text { (EIB) }\end{array}$ & $\begin{array}{l}\text { https://www.e b.org/en } \\
\text { index.htm }\end{array}$ & NO & NO & Sí & Sí & NO & Si & NO & NO \\
\hline $\begin{array}{l}\text { European Data } \\
\text { Protector } \\
\text { Supervisor } \\
\text { (EDPS) }\end{array}$ & $\begin{array}{l}\frac{\text { https:/ledps.europa.e }}{\text { ufedps-homepage en }} \\
\text { ?lang=en }\end{array}$ & $\overline{N O}$ & NO & NO & Si & Si & Si & NO & NO \\
\hline $\begin{array}{l}\text { The European } \\
\text { Data Protection } \\
\text { Board (EDPB) }\end{array}$ & $\begin{array}{l}\text { https://edpb.europa.e } \\
\text { uledpb en }\end{array}$ & $\overline{\mathrm{si}}$ & si & NO & Sí & Si & NO & NO & NO \\
\hline
\end{tabular}




\begin{tabular}{|c|c|c|c|c|c|c|c|c|c|}
\hline \multirow[b]{2}{*}{ INSTITUCIÓN } & \multirow[b]{2}{*}{ uri } & \multicolumn{8}{|c|}{ CONTENIDO } \\
\hline & & Logotipo & $\begin{array}{l}\text { Identificación } \\
\text { como ente de } \\
\text { la UE (.eu) }\end{array}$ & Tone of voice & \begin{tabular}{|l|} 
Posicionami \\
ento/descript \\
ivo/claim
\end{tabular} & Tipología de Imágenes & Diseño & \begin{tabular}{|l|} 
Lenguaje \\
infográfico
\end{tabular} & $\begin{array}{l}\text { Videos } \\
\text { didácticos }\end{array}$ \\
\hline $\begin{array}{l}\text { European } \\
\text { Parliament }\end{array}$ & \begin{tabular}{|l|} 
hittos:/iwwww.europarl.e \\
uropa.eulportal/en
\end{tabular} & $\overline{\text { Si }}$ & si & $\begin{array}{l}\text { Directo, } \\
\text { sencillo, } \\
\text { empatico. } \\
\text { ilustrativo. }\end{array}$ & NO & $\begin{array}{l}\text { Modernas en general pero demasiado básicas en } \\
\text { algunos casos. }\end{array}$ & Funcional & Si & si \\
\hline $\begin{array}{l}\text { European Council } \\
\text { /Council of the } \\
\text { European Union }\end{array}$ & 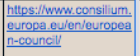 & si & si & $\begin{array}{l}\text { Insitucional, } \\
\text { corporativo. }\end{array}$ & $\begin{array}{l}\text { Si: Council of } \\
\text { the European } \\
\text { Union }\end{array}$ & $\begin{array}{l}\text { Folografias (Institucionales, informativas) e } \\
\text { ilustraciones. }\end{array}$ & Funcional & Si & Si \\
\hline $\begin{array}{l}\text { Presidency of the } \\
\text { Council of the EU }\end{array}$ & 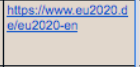 & si & si & \begin{tabular}{|l|} 
Adecuado \\
especificament \\
e a cada \\
sección.
\end{tabular} & NO & $\begin{array}{l}\text { Mixta: institucional, descriptiva, inspiradora, según los } \\
\text { contenidos. Notable criterio grafico. En general } \\
\text { manfifestan optimismo y la positividad. }\end{array}$ & $\begin{array}{l}\text { Limpio, claro, } \\
\text { usable. }\end{array}$ & NO & si \\
\hline $\begin{array}{l}\text { European Central } \\
\text { Bank }\end{array}$ & \begin{tabular}{|l|} 
hittps:/Wwww.ecb.europ \\
a.euhome.htmlindex \\
en.html
\end{tabular} & si & si & \begin{tabular}{|l|} 
Directo, \\
apelando a \\
conocer más,
\end{tabular} & \begin{tabular}{|l|} 
Si. \\
Eurosystem
\end{tabular} & $\begin{array}{l}\text { Insittucionales, tecnológicas, y banco de imagen. Las } \\
\text { inst tucionales giran en torno a la figura de Christine } \\
\text { Lagarde }\end{array}$ & Antiguo & NO & Si \\
\hline $\begin{array}{l}\text { European Court } \\
\text { of Auditors }\end{array}$ & \begin{tabular}{|l} 
hitps:/Www.eca.europ \\
a.eulen/Pages/ecadef \\
ault.aspx \\
\end{tabular} & $\overline{\text { si }}$ & Sí & $\begin{array}{l}\text { Impersonal, } \\
\text { trio. }\end{array}$ & $\begin{array}{l}\text { Si: Guardians } \\
\text { of the EU } \\
\text { finances }\end{array}$ & Banco de imagen & Antiguo & NO & NO \\
\hline $\begin{array}{l}\text { European Union } \\
\text { External Action } \\
\text { Service }\end{array}$ & 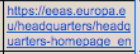 & Sí & sí & $\begin{array}{l}\text { Informativo, } \\
\text { práctico }\end{array}$ & $\begin{array}{l}\text { Si: External } \\
\text { Action }\end{array}$ & Banco de imagen & $\begin{array}{l}\text { Modemo, claro, } \\
\text { usable. }\end{array}$ & NO & NO \\
\hline $\begin{array}{l}\text { European } \\
\text { Economic and } \\
\text { Social Comm ttee } \\
\text { (EESC) }\end{array}$ & $\begin{array}{l}\text { hitpos:/Www.eesc.euro } \\
\text { pa.eulen }\end{array}$ & Si & Sí & \begin{tabular}{|l|} 
Informativo de \\
modo \\
impersonal
\end{tabular} & NO & Folografias (pocas y de lideres) & $\begin{array}{l}\text { Tipo blog, algo } \\
\text { desfasado }\end{array}$ & NO & NO \\
\hline $\begin{array}{l}\text { European } \\
\text { Committee of the } \\
\text { Regions (CoR) }\end{array}$ & $\begin{array}{l}\text { htlps:llcoreuropa euf } \\
\text { enl }\end{array}$ & Si & Sí & $\begin{array}{l}\text { Descriptivo, } \\
\text { informativo. }\end{array}$ & NO & $\begin{array}{l}\text { Banco de imagen, fotos personales, ilustraciones. Falta } \\
\text { de criterio. }\end{array}$ & $\begin{array}{l}\text { Tipo blog, algo } \\
\text { desfasado }\end{array}$ & NO & NO \\
\hline $\begin{array}{l}\text { The European } \\
\text { Data Protection } \\
\text { Board (EDPB) }\end{array}$ & $\begin{array}{l}\text { hittps:/fedpb.europa.e } \\
\text { uledob en }\end{array}$ & $\overline{\text { si }}$ & Si & \begin{tabular}{|l|} 
Institucional e \\
informativo.
\end{tabular} & \begin{tabular}{|l|} 
European \\
Data \\
Protection \\
Board
\end{tabular} & Iconográfica & $\begin{array}{l}\text { Tipo blog, algo } \\
\text { desfasado }\end{array}$ & NO & NO \\
\hline
\end{tabular}




\begin{tabular}{|c|c|c|c|c|c|c|c|}
\hline \multirow[b]{2}{*}{ INSTITUCIÓN } & \multirow[b]{2}{*}{ url } & \multicolumn{6}{|c|}{ USABILIDAD Y ACCESIBILIDAD } \\
\hline & & Buscador & \begin{tabular}{|l|} 
Selección \\
idioma
\end{tabular} & \begin{tabular}{|l|} 
Contacto \\
con \\
equipo \\
web
\end{tabular} & $\begin{array}{l}\text { Menú fijo al } \\
\text { hacer scroll }\end{array}$ & \begin{tabular}{|l|} 
Aprovech \\
amiento \\
de \\
convencio \\
nes
\end{tabular} & $\begin{array}{l}\text { Lectura para } \\
\text { discapacitad } \\
\text { os (auditivos } \\
\text { finvidentes) }\end{array}$ \\
\hline $\begin{array}{l}\text { EUROPEAN } \\
\text { UNION }\end{array}$ & $\begin{array}{l}\text { https:/leuropa.eu/european-uni } \\
\text { on/index en }\end{array}$ & sí & si & si & NO & si & NO \\
\hline $\begin{array}{l}\text { European } \\
\text { Parliament }\end{array}$ & $\begin{array}{l}\text { https://www.europarl.europa.eu } \\
\text { jportal/en }\end{array}$ & Si & Si & Si & Si & Si & Si \\
\hline $\begin{array}{l}\text { European Council } \\
\text { / Council of the } \\
\text { European Union }\end{array}$ & $\begin{array}{l}\text { https://www.consilium.europa.e } \\
\text { u/en/european-councily }\end{array}$ & si & si & Si & NO & Si & Si \\
\hline $\begin{array}{l}\text { Presidency of the } \\
\text { Council of the EU }\end{array}$ & $\begin{array}{l}\text { https://www.eu2020.deleu2020- } \\
\text { en }\end{array}$ & si & Si & Si & si & Si & si \\
\hline $\begin{array}{l}\text { European } \\
\text { Commission }\end{array}$ & $\begin{array}{l}\text { https://ec.europa.eu/info/index } \\
\text { en }\end{array}$ & Si & Si & Si & NO & NO & NO \\
\hline $\begin{array}{l}\text { Court of justice of } \\
\text { the European } \\
\text { Union }\end{array}$ & $\begin{array}{l}\text { https://curia.europa.eu/icms/ic } \\
\text { ms/i 6/en/ }\end{array}$ & si & Si & NO & NO & NO & NO \\
\hline $\begin{array}{l}\text { European Central } \\
\text { Bank }\end{array}$ & $\begin{array}{l}\text { https://www.ecb.europa.eu/hom } \\
\text { e/html/index.en.html }\end{array}$ & Si & Si & NO & NO & NO & NO \\
\hline $\begin{array}{l}\text { European Court } \\
\text { of Auditors }\end{array}$ & $\begin{array}{l}\text { https://www.eca.europa.eu/en/ } \\
\text { Pages/ecadefaultaspx }\end{array}$ & Si & Si & NO & NO & Si & NO \\
\hline $\begin{array}{l}\text { European Union } \\
\text { External Action } \\
\text { Service }\end{array}$ & $\begin{array}{l}\text { hittps://eeas.europa.eu/headqu } \\
\text { arters/headquarters-homepage } \\
\text { en }\end{array}$ & Si & Si & NO & si & Sí & NO \\
\hline $\begin{array}{l}\text { European } \\
\text { Economic and } \\
\text { Social Committee } \\
\text { (EESC) }\end{array}$ & https://www.eesc.europa.eu/en & Si & Si & Si & NO & NO & si \\
\hline $\begin{array}{l}\text { European } \\
\text { Committee of the } \\
\text { Regions (CoR) }\end{array}$ & https:/icor.europa.euleny & Si & Si & NO & NO & NO & NO \\
\hline $\begin{array}{l}\text { European } \\
\text { Investment Bank } \\
\text { (EIB) }\end{array}$ & $\begin{array}{l}\text { https://www.eib.org/en/index.ht } \\
\text { m }\end{array}$ & Sí & Si & Si & NO & Si & NO \\
\hline $\begin{array}{l}\text { European Data } \\
\text { Protector } \\
\text { Supervisor } \\
\text { (EDPS) }\end{array}$ & $\begin{array}{l}\text { https://edps.europa.eu/edps-ho } \\
\text { mepage en?lang=en }\end{array}$ & Si & Si & NO & si & si & NO \\
\hline $\begin{array}{l}\text { The European } \\
\text { Data Protection } \\
\text { Board (EDPB) }\end{array}$ & $\begin{array}{l}\text { https://edpb.europa.eu/edpb e } \\
\underline{\text { n }}\end{array}$ & Sí & Si & NO & NO & NO & NO \\
\hline
\end{tabular}


